\title{
3D standard brain of the red flour beetle Tribolium castaneum: a tool to study metamorphic development and adult plasticity
}

\section{David Dreyer ${ }^{1,2}$, Holger Vitt' , Stefan Dippel ${ }^{1,3}$, Brigitte Goetz $^{1}$, Basil el Jundi ${ }^{1}$, Martin Kollmann $^{1}$, Wolf Huetteroth $^{1,4}$ and Joachim Schachtner ${ }^{1 *}$}

\author{
'Department of Biology, Animal Physiology, Philipps-University Marburg, Marburg, Germany \\ 2 Department of Biology, Animal Navigation, University of Oldenburg, Oldenburg, Germany \\ ${ }^{3}$ Department of Developmental Biology, Johann-Friedrich-Blumenbach-Institute for Zoology and Anthropol, Georg-August-University Göttingen, Göttingen, Germany \\ ${ }^{4}$ Department of Neurobiology, University of Massachusetts Medical School, Worcester, MA, USA
}

Edited by:

Randolf Menzel, Freie Universität Berlin, Germany

Reviewed by:

Monika Stengl, Universität Kassel,

Germany

\section{*Correspondence:}

Joachim Schachtner, Department of Biology, Animal Physiology, PhilippsUniversity Marburg, Karl-von-Frisch-Str. 8, D-35032 Marburg, Germany. e-mail: schachtj@staff.uni-marburg.de

\begin{abstract}
The red flour beetle Tribolium castaneum is emerging as a further standard insect model beside Drosophila. Its genome is fully sequenced and it is susceptible for genetic manipulations including RNA-interference. We use this beetle to study adult brain development and plasticity primarily with respect to the olfactory system. In the current study, we provide 3D standard brain atlases of freshly eclosed adult female and male beetles (A0). The atlases include eight paired and three unpaired neuropils including antennal lobes (ALs), optic lobe neuropils, mushroom body calyces and pedunculi, and central complex. For each of the two standard brains, we averaged brain areas of 20 individual brains. Additionally, we characterized eight selected olfactory glomeruli from $10 \mathrm{~A} 0$ female and male beetles respectively, which we could unequivocally recognize from individual to individual owing to their size and typical position in the ALs. In summary, comparison of the averaged neuropil volumes revealed no sexual dimorphism in any of the reconstructed neuropils in A0 Tribolium brains. Both, the female and male 3D standard brain are also used for interspecies comparisons, and, importantly, will serve as future volumetric references after genetical manipulation especially regarding metamorphic development and adult plasticity.
\end{abstract}

Keywords: brain, olfactory system, antennal lobe, insect, neuropil, digital neuroanatomy, coleoptera

\section{INTRODUCTION}

The red flour beetle Tribolium castaneum Herbst, 1797 (Bonneton, 2008), which is a major pest of stored grains, grain products, and other dried food, is emerging as a further standard insect model beside Drosophila. It's powerful reverse genetics (systemic RNA-interference; Bucher et al., 2002; Tomoyasu and Denell, 2004; Tomoyasu et al., 2008), the recently published full genomic sequence (Richards et al., 2008) and the established transgenesis systems (Berghammer et al., 1999) transform Tribolium into a primary model system. Since recently, an insertional mutagenesis screen database provides mutants and enhancer trap lines for the growing Tribolium community (http://134.76.20.145/ Default.aspx). Meanwhile, Tribolium has become one of the most important models in the field of evolution and development ("evo-devo") because its development is more "insect typical", compared to that of the classical system Drosophila (Klingler, 2004). Currently, only little information on the brain or its embryonic and metamorphic development is available. With our pioneering study we provide for the first time anatomical descriptions for most of the brain areas of adult Tribolium including $3 \mathrm{D}$ reconstructions and an average brain atlas for selected brain neuropils. With the latter, we present the first standardization of a coleopteran brain.

Brains are typically organized in defined neuropils, which can usually be characterized by their spatial location, gross anatomy, and often by a certain function. For example, the olfactory bulbs of vertebrates and the antennal lobes (ALs) of insects have been attributed to be the first processing centers for olfactory information (for a review see Hildebrand and Shepherd, 1997). Compared to most vertebrate brains, insect brains are miniature versions being typically comprised of a lower number of neurons and neuropils. Owing to the lower complexity and certain technical advantages, insects have been widely used as models to study principal mechanisms of information processing and integration, in the context of defined sensory inputs but also complex behaviors including learning and memory formation (e.g. Menzel, 2001; Heisenberg, 2003).

Brains of animals of the same or of evolutionary related species typically share the same principal organization. For example in neopteran insects, the central olfactory pathway seems to be well conserved (Strausfeld et al., 1998; Schachtner et al., 2005). However, even within the same species, no brain is identical with the next, differing in size and shape of certain brain neuropils. These individual differences can result from a variety of parameters which are influencing brain organization during development but also during adulthood. In insects, such factors include brood temperature, sex, age, and experience (Groh et al., 2004; Technau, 2007; Molina and O’Donnell, 2008).

To study sexual brain dimorphism or the influence of defined parameters (ranging from single molecules to social experience) on brain development or adult plasticity, average or standardized brains or brain areas are needed to relate individual variations to 
each other. Advances in imaging techniques, 3D reconstruction software, and computer power led so far to $3 \mathrm{D}$ reconstructions and subsequent standardization of brain areas of four insect species including Drosophila melanogaster (Rein et al., 2002; Jenett et al., 2006), the honeybee Apis mellifera (Brandt et al., 2005), the desert locust Schistocerca gregaria (Kurylas et al., 2008), and the sphinx moth Manduca sexta (el Jundi et al., 2009). To obtain such a standard insect brain, two methods have so far been established: The virtual insect brain (VIB) protocol and the iterative shape averaging (ISA) method. While the VIB protocol was mainly developed to compare wild type and genetically manipulated Drosophila (Rein et al., 2002; Jenett et al., 2006), the ISA method, first used for the honeybee, was aimed to register single reconstructed neurons from various individuals into one standard brain (Rohlfing et al., 2004; Brandt et al., 2005). Although the ISA method provides a far better representation of relative locations of brain areas, this high registration quality comes with the tradeoff of missing volumetric consistency for the neuropils. This means, a neuropil label of the standardized ISA brain does not represent the mean volume of all corresponding individual neuropil labels (Kuß et al., 2007; Kurylas et al., 2008). Thus, the VIB script remains advantageous for fast inter- and intraspecific comparisons of neuropils including sexspecific differences, while preserving volumetric consistency.

In the current study, we reconstructed in three dimensions and subsequently standardized brain areas of both sexes of the red flour beetle Tribolium castaneum using the VIB protocol. The aims of our study were to (1) compare adult brain neuropil volumes regarding sexual dimorphism (2) provide an adult female and male standard brain at A0 (freshly eclosed adults) as volume references for future genetical and behavioral studies, and (3) to compare the standard volumes of brain areas with previously published standard volumes of homologous brain areas of other neopteran insects. To obtain the desired datasets we labeled whole brains with an antiserum against the synaptic vesicle protein synapsin to visualize neuropil areas, analyzed the staining using confocal laser scanning microscopy, $3 \mathrm{D}$ reconstructed the selected brain neuropils using the software AMIRA (Visage Imaging, Fürth, Germany), and subsequently registered and standardized the neuropils using the (VIB) protocol. A standardization using the ISA method can be computed on request. Comparing the standardized neuropil volumes between females and males revealed no obvious sexual dimorphism in A0 Tribolium brains.

\section{MATERIALS AND METHODS ANIMALS}

Wild type Tribolium castaneum (San Bernardino; Sokoloff, 1966) stock for egg laying was kept in plastic boxes $(20 \times 18 \times 18 \mathrm{~cm})$ in walk-in environmental chambers at $26^{\circ} \mathrm{C}$ under constant darkness. The boxes were half filled with substrate containing organic whole wheat flour supplemented with 5\% dried yeast powder. To prevent sporozoan infections we added $0.05 \%$ (w/w) Fumidil-B (J. Webster Laboratories Inc., Princeville, Kanada; Berghammer et al., 1999).

For egg collection, we used similar procedures as described in Berghammer et al. (1999). The beetles were kept for 2 days in substrate and then separated from the substrate with a stainless steel sieve (710- $\mu \mathrm{m}$ mesh size; Retsch, Haan, Germany) to be transferred into a box filled with instant flour (type 405; Aurora
Mühlen GmbH, Hamburg, Germany) for egg laying. After 2 days in instant flour, the beetles were separated again with the $710-\mu \mathrm{m}$ sieve and the eggs fetched with a fine sieve $(300-\mu \mathrm{m}$ mesh size, Retsch, Haan, Germany). Instant flour was used for collecting eggs, because it becomes less clotted und does thus not clog the sieves in contrast to the normal white flour (Berghammer, et al., 1999). Eggs were then transferred into a separate box filled with fresh substrate. To optimize egg-laying performance, separated beetles were transferred back to substrate (Sokoloff, 1974). This separation technique was used to avoid the contamination of the substrate with secretions of the parents e.g. benzoquinones, because they can heavily influence the development of the larvae (Chapman, 1926; Happ, 1968; Sokoloff, 1974, 1977). The collected eggs were kept in substrate in smaller boxes $(20 \times 12 \times 4 \mathrm{~cm})$ in an incubator at $30^{\circ} \mathrm{C}$ and constant darkness. After about 4 weeks, the first beetles finished metamorphosis and freshly eclosed beetles (A0) could be collected. A0 beetles can be easily distinguished from older beetles by their white cuticle and their slow movement.

\section{IMMUNOHISTOCHEMISTRY}

For wholemount staining we adapted and refined the protocols described by Huetteroth and Schachtner (2005) and el Jundi et al. (2009). Whole brains were dissected in a drop of cold PBS (phosphate-buffered saline, $0.01 \mathrm{M}, \mathrm{pH} 7.4$ ) and fixed subsequently in $4 \%$ formaldehyde (Roth, Karlsruhe, Germany) in 0.01-M PBS for $1-2 \mathrm{~h}$ at room temperature. The brains were then rinsed five times for $10 \mathrm{~min}$ at room temperature in $0.01 \mathrm{M} \mathrm{PBS}$ followed by preincubation for $1-2$ days at $4{ }^{\circ} \mathrm{C}$ in $5 \%$ normal goat serum (NGS; Jackson ImmunoResearch, Westgrove, PA, USA) in 0.01 M PBS containing $0,3 \%$ Triton X-100 (PBST). The monoclonal primary antibody from mouse against a fusion protein consisting of a glutathione-S-transferase and the first amino acids of the presynaptic vesicle protein synapsin I coded by its $5^{\prime}$-end (SYNORF1, Klagges et al., 1996) was used to selectively label neuropilar areas in the brain (3C11, \#151101 (13.12.06), kindly provided by Dr. E. Buchner, Würzburg). Its specificity in T. castaneum was shown with Western blot (Utz et al., 2008). The brains were incubated in a 1:100 dilution of the synapsin antibody in PBST containing $2 \%$ NGS for $2-3$ days at $4^{\circ} \mathrm{C}$. Subsequently the brains were rinsed three times for $15 \mathrm{~min}$ with PBST before they were incubated with the secondary goat anti-mouse antibody conjugated to Cy5 (1:300, catalog code 115-175-146, lot 71608, Jackson ImmunoResearch, Westgrove, PA, USA) in PBST and 1\% NGS for 2 days at $4{ }^{\circ} \mathrm{C}$. Afterwards the brains were rinsed again with PBST five times for $10 \mathrm{~min}$ and subsequently dehydrated in an ascending ethanol series $(50 \%, 70 \%, 90 \%, 95 \%$, and two times $100 \%$, for $2.5 \mathrm{~min}$ each) and then cleared in methyl salicylate (Merck, Gernsheim, Germany), until the tissue was transparent. At last the brains were mounted in Permount (Fisher Scientific, Pittsbourgh, PA, USA) between two coverslips using two reinforcing rings as spacers (Zweckform, Oberlaindern, Germany) to prevent compression of brains.

\section{CLSM IMAGE ACOUISITION AND PROCESSING}

The wholemount preparations for the standard brains were scanned with a confocal laser scanning microscope (CLSM, Leica TCS SP2) at $512 \times 512$ pixel resolution by using a $40 \times$ oil immersion objective 
(HCX PL APO 40×/1.25-0.75 Oil CS (working distance: $0.1 \mathrm{~mm}$ ); Leica, Bensheim, Germany). All brains were scanned with a voxel size of $0.73 \times 0.73 \times 0.5 \mu \mathrm{m}$, a speed of $200 \mathrm{~Hz}$, a pinhole of 1 Airy unit and a line average of $2-4$.

ALs were scanned at $1024 \times 1024$ pixel resolution with a $63 \times$ oil immersion objective (HCX PL APO 63×/1.32-0.60, Oil Ph3 CS (working distance: $70 \mu \mathrm{m}$ ); Leica, Bensheim, Germany) or a $40 \times$ oil immersion objective (HCX PL APO 40×/1.25-0.75 Oil CS (working distance: $0.1 \mathrm{~mm}$ ); Leica, Bensheim, Germany) using a Leica TCS SP2 CLSM or with a $63 \times$ glycerol objective (HCX PL APO $63 \times / 1.30 \mathrm{Glyc} 21^{\circ} \mathrm{C} \mathrm{CS}$ (working distance: $0.26 \mathrm{~mm}$ ); Leica, Bensheim, Germany) using a Leica TCS SP5 CLSM. Depending on the zoom factor (1-4), the different CLSM and different objectives we scanned with varying voxel sizes $0.07-0.16 \times 0.07-0.16 \times 0.5-$ $1 \mu \mathrm{m}$. ALs were scanned with a speed of $200-400 \mathrm{~Hz}$, a pinhole of 1 Airy unit and a line average of $2-4$.

\section{IMAGE SEGMENTATION, RECONSTRUCTION, STANDARDIZATION AND VISUALIZATION}

The selected 19 neuropils of the male and female brains were labeled with the segmentation editor in AMIRA 4.1 (Visage Imaging, Fürth, Germany). For the eight individual glomeruli of the right ALs we used AMIRA 5.2.1. For the segmentation and reconstruction details we refer to Kurylas et al. (2008). In short, semi-automatically created voxel-based label fields of eight paired and three unpaired neuropilar structures in 20 female and 20 male $T$. castaneum brains provided the underlying matrix of all computation processes performed (i.e. polygonal surface models, morphometric analysis, and shape averaging). For orientation guidance, brain outlines were reconstructed separately. This label field however was not standardized. The color code for neuropils of the standard brains is consistent with Brandt et al. (2005), Kurylas et al. (2008), and el Jundi et al. (2009). We offer the AMIRA label fields with color codes as online download (Supplement 1). The orientation of the brain structures is given with respect to the body axis.

The VIB protocol used for registration and standardization was described in detail by Jenett et al. (2006) and is available at http:// www.neurofly.de. The functions of the VIB protocol are integrated features of the AMIRA graphical environment. The application of the VIB protocol requires a template brain which defines the position of individual neuropils in the visualized standard brain. To overcome a subjective bias, we selected the template brains according to optimal position and symmetry of the reconstructed neuropils. The selection contained three steps. First, according to Kurylas et al. (2008) and el Jundi et al. (2009) we calculated the distances of the centers of each of the reconstructed neuropils to the center of the respective brain. All distances for each brain were summed up, and the differences to the mean distance were calculated for all 20 brains of each sex respectively. In a second step, we calculated the symmetry of the brain areas by calculating the difference of the angles between the vectors connecting the centers of the neuropils. To obtain the angles, we calculated the vectors between the centers of the paired neuropils using the scalar product. In this way, we calculated angles between three neuropil pairs (AL-Me, AL-Ca, Ca-Me). The sum of the three angles served as the symmetry criterion. Both, the results of the distance and the angle calculations were normalized, with the worst brain set to one for each criterion. In the resulting combined ranking, the normalized values of both criteria were added. The third criterion for the choice of the template brain was a visual inspection of the three best ranked brains for each sex respectively. For the male template, we choose the brain ranking at number one according to the first two criteria. For the female template we choose number two, because visual inspection of the three best ranked brains revealed that the left peduncle of female brain number one was somehow twisted towards the midline. In the female ranking, brains number one and two were very close together. The choice of the template brain does not influence the resulting standard volumes (Kurylas et al., 2008). For creation of standard brain neuropil labels, we chose an overlap threshold of $40 \%$ for all neuropils.

The statistical analysis of these data was obtained using Excel $\mathrm{XP}$ for Windows. The synapsin-immunoreactivity (syn-ir) in Figures 1 and 5 was auto-contrasted in the OrthoSlice module of AMIRA. For visualization, neuropils segmented in AMIRA, were filled with transparent colored labels using Adobe Photoshop 8 (Adobe Systems, San Jose, CA, USA). Snapshots taken in AMIRA and Pictures edited in Photoshop (Figures 1-3 and 5), and diagrams generated with Excel XP (Figures 4 and 6) were imported to Corel Draw 13 (Corel Corporation, Ottawa, Ontario, CA, USA) without any further modification.

\section{RESULTS RECONSTRUCTED NEUROPILS}

Of all major areas of the Tribolium brain we reconstructed those which we were able to unambiguously delimit in all three dimensions (8 paired and 3 unpaired neuropils). In the optic lobes, we reconstructed the medulla (Me), the lobula (Lo), the lobula plate $(\mathrm{LoP})$, and the accessory medulla $(\mathrm{aMe})$ (Figures 1A-d, B-c' and 2). The LoP which lays posterior to the Lo is exclusively found in Ephemeroptera, Trichoptera, Coleoptera, Lepidoptera, Diptera (Strausfeld, 2005), and Heteroptera (Settembrini and Villar, 2005).

In the central brain we divided the mushroom body into two neuropils, the pedunculus $(\mathrm{Pe})$, which contained the vertical lobe $(\mathrm{vL})$ and medial lobe $(\mathrm{mL})$, and the calyx $(\mathrm{Ca})$ (Figures 1A-b, $\mathbf{B}-\mathbf{a}^{\prime}, \mathbf{b}^{\prime}$ and 2). Although visible in the synapsin immunostaining, we refrained from including subunits of the pedunculus described for the moth Spodoptera littoralis (Sjöholm et al., 2005) or Bombyx mori (Fukushima and Kanzaki, 2009); the resulting complexity of the pedunculus would have greatly interfered with standardization procedures, and would have also interfered with interspecies comparison. Nevertheless, with the exception of the $\beta^{\prime}$-, and $\gamma$-lobe, which lay very tight together and which typically are one protrusion after reconstruction, the other lobes of the pedunculus, the $\alpha-, \alpha^{\prime}-$, and $\beta$ - lobe (Zhao et al., 2008) are discernible protrusions in our reconstructions (Figure 2). Between the left and right mushroom body lies the central complex, which comprises the protocerebral bridge (PB), the upper and lower unit of the central body (CBU, $\mathrm{CBL}$ ) and a small paired neuropil ventrally attached to the central body, the noduli (No) (Figures 1A-c,e,f,,B-b' and 2). The anteriormost labeled neuropils were the deutocerebral antennal lobes (AL, Figures 1A-a and 2). 


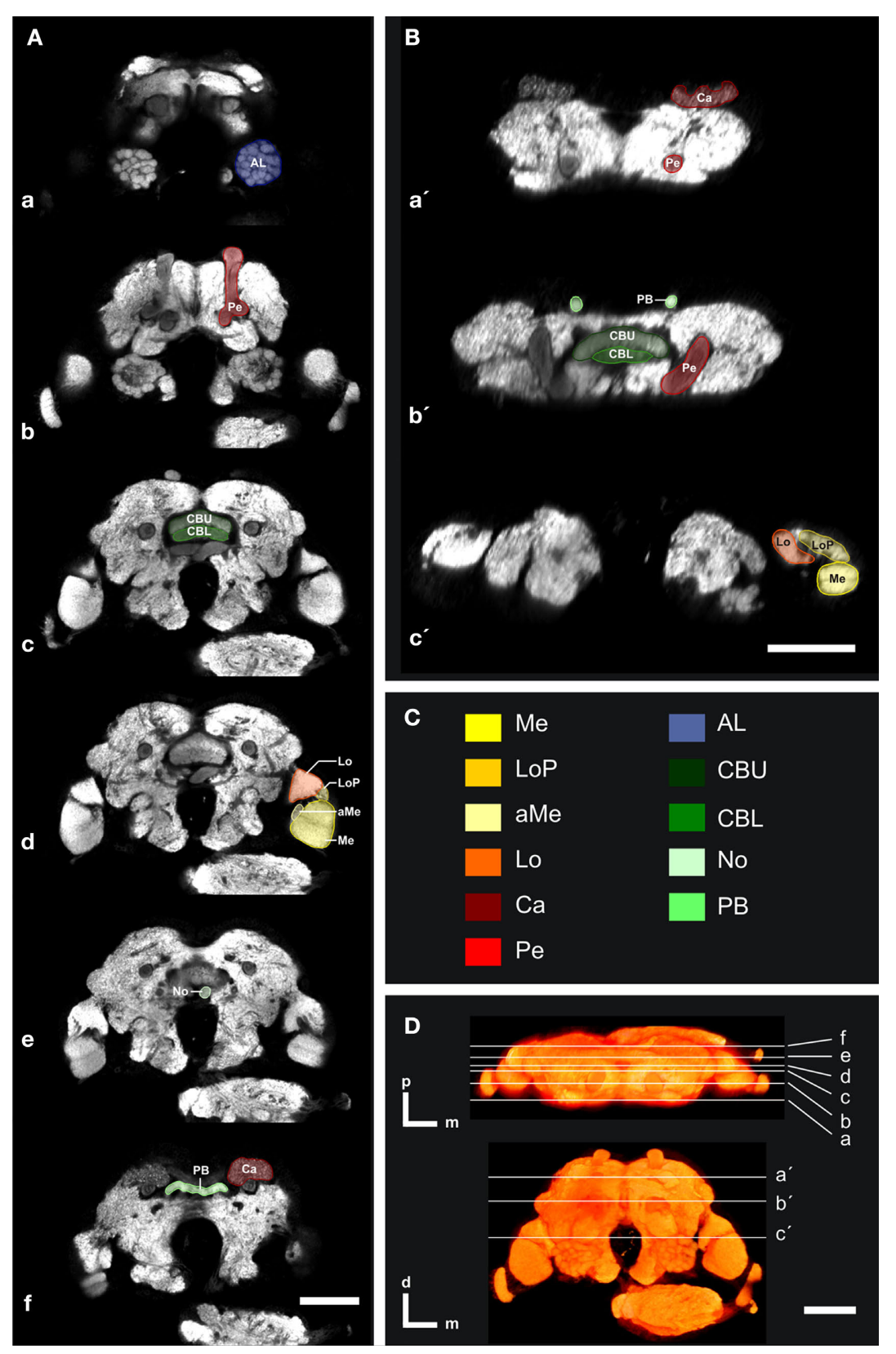

FIGURE 1 | Confocal images of the individual T. castaneum brain stained with an antibody against synapsin which was used as template for the VIB protocol. (A, B) Single optical sections through the brain in the frontal (A) and horizontal plane (B). All manually labeled neuropil areas are shown as reconstructed in AMIRA. Labels of paired neuropils are only visualized in the left hemispheres, to provide a comparison to the unlabeled neuropils of the right hemispheres. (A) Frontal sections with the positions a-f from anterior to posterior and as described in (D). (B) Horizontal sections with the positions $a^{\prime}-c^{\prime}$ from dorsal to ventral as described in (D). (C) The color code of the labeled neuropils is consistent with Brandt et al. (2005), Kurylas et al. (2008), and el Jundi et al. (2009). $\mathrm{AL}$, antennal lobe; $\mathrm{Ca}$, Calyx; $\mathrm{CBL}$, lower unit of the central body; $\mathrm{CBU}$, upper unit of the central body; aMe, accessory medulla; Lo, lobula; LoP, lobula plate; Me, medulla; No, nodulus; PB, protocerebral bridge; and Pe, pedunculus with lobes. (D) Volume rendered (Voltex) view of the template brain from dorsal and frontal. The sections (a-f) and $\left(\mathbf{a}^{\prime}-\mathbf{c}^{\prime}\right)$ represent the positions of the optical sections in (A,B). Orientation bars, p, posterior; m, median; d, dorsal. All scale bars, $50 \mu \mathrm{m}$.
Representative outlines of all labels of these selected neuropils are shown in frontal and horizontal slices (Figure 1), an animation of all orthogonal sections of this brain can be found in the supplementary material (Supplement 2). Additionally, all reconstructed neuropils are displayed three-dimensionally to provide a $3 \mathrm{D}$ visualization of the whole brain (Figure 2).

\section{THE STANDARD BRAINS}

To apply the VIB protocol on the $3 \mathrm{D}$ brain reconstructions, one brain reconstruction had to be chosen as positional reference (Jenett et al., 2006). To reduce a subjective bias, we selected the template brains according to (1) position and (2) symmetry of the reconstructed neuropils, and (3) final visual inspection of the 


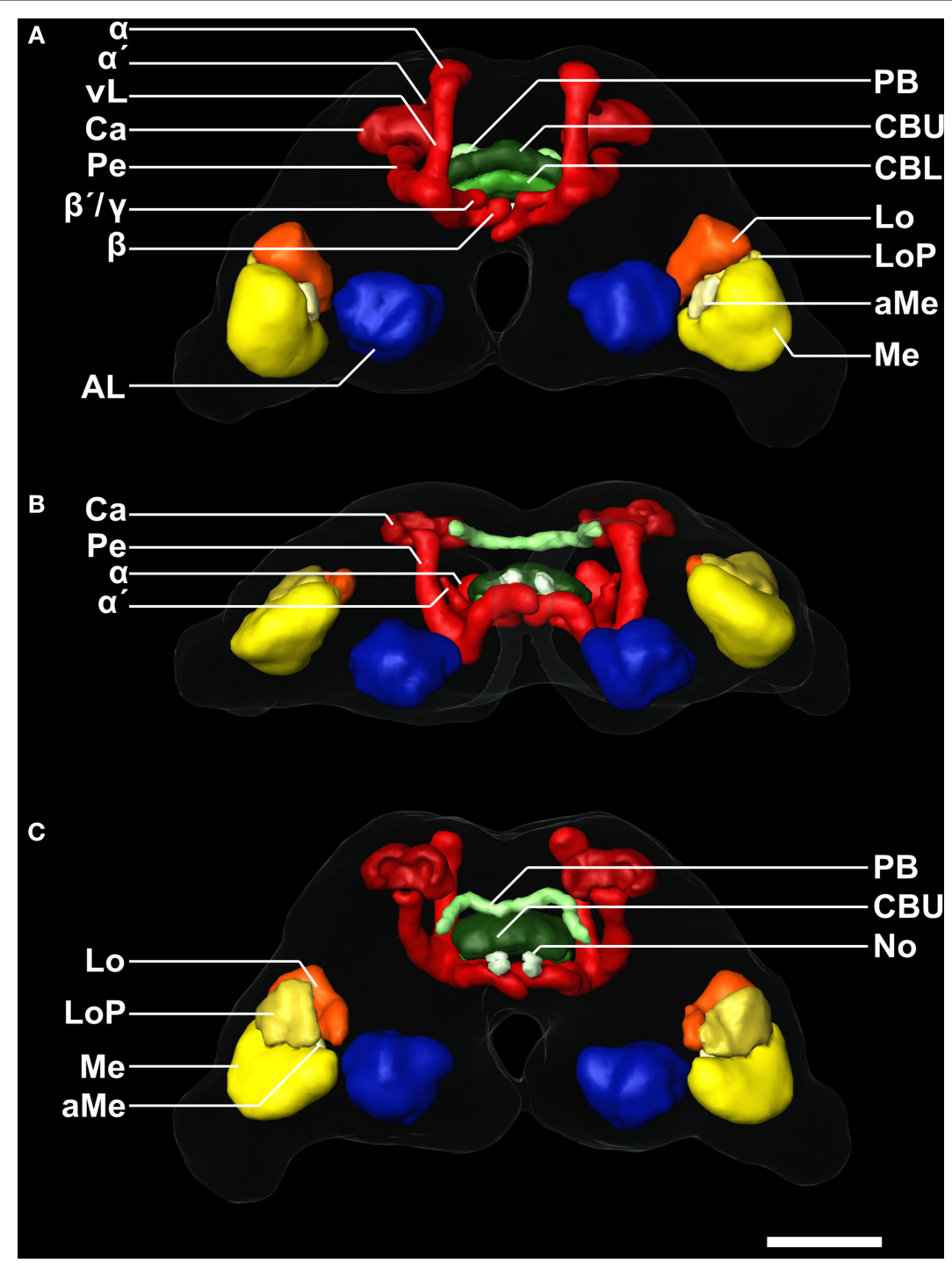

FIGURE 2 | 3D reconstruction of the male template brain of $T$. castaneum in (A) anterior (B) ventral, and (C) posterior view. The neuropils were visualized with the AMIRA tools SurfaceGen and Surfaceview. Note that the $\alpha$ and $\alpha^{\prime}$ lobes of the medial lobes can be clearly distinguished. In the medial lobes, the $\beta$-lobes are visible, while the second protrusion represents the $\beta^{\prime}$ - and the $\gamma$-lobes which were not discernable in the reconstruction. $v L$, vertical lobe. See Figure 1 for color code and abbreviations. Scale bar, $50 \mu \mathrm{m}$. three best brains resulting from criteria one and two (see Section "Materials and Methods"). The template brain used for generating the male standard brain is shown in Figures 1 and 2.

For the female and the male standard brain we reconstructed selected neuropils of 20 individual female and 20 individual male brains of freshly eclosed (A0) T. castaneum. With the VIB protocol we generated three-dimensional standard atlases of both sexes consisting of 19 neuropils (eight paired and three unpaired neuropils), including both hemispheres of the brain. The neuropil surface model and the corresponding average intensity map produced by direct volume rendering of the male standard brain are shown in Figures $\mathbf{3 A}-\mathbf{C}, \mathbf{A}^{\prime}-\mathbf{C}^{\prime}$ from anterior, ventral and posterior. Volume rendering of all 20 label images after non-rigid registration reveal the high quality of registration (Figures 3D,E). Clear deviations are only visible in the vL of the MBs (Figures 3D,E). An animated view of the male standard brain can be seen in the online supplement (Supplement 3).

\section{COMPARISON OF THE FEMALE AND MALE BRAINS}

The VIB protocol also generates the standard volumes for each of the reconstructed brain areas of the 20 female and 20 male brains respectively. Table 1 gives mean volumes, standard deviation and standard error of absolute and relative volumes of all 19 areas. Within each sex, a comparison of the volumes of the corresponding left and right brain neuropils using the two-tailed student t-test revealed no significant difference (not shown). Comparing the volumes of corresponding neuropils between females and males resulted also in no significant difference (Figure 4). 

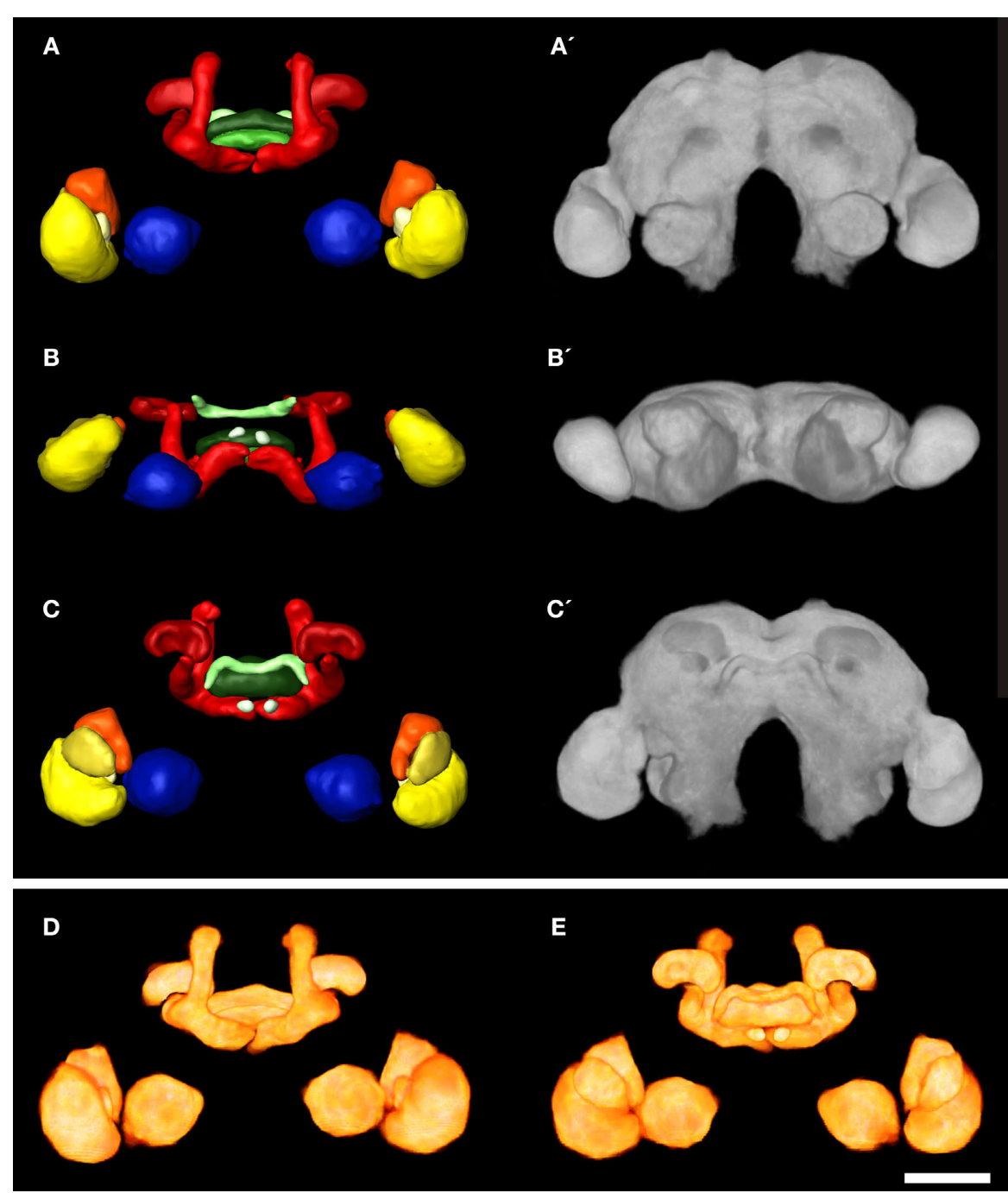

FIGURE 3 | 3D male standard brain of $T$. castaneum calculated from 20 individual brains by using the VIB protocol. (A-C) Surface reconstructions of all 18 averaged labels in (A) anterior (B) ventral, and (C) posterior view. The brain surface (as in $\mathbf{A}^{\prime}-\mathbf{C}^{\prime}$ ) is not labeled. See Figure $\mathbf{1}$ for color code. $\left(\mathbf{A}^{\prime}-\mathbf{C}^{\prime}\right)$ 3D visualization of the corresponding average intensity map by direct volume rendering with $\left(\mathbf{A}^{\prime}\right)$ anterior $\left(\mathbf{B}^{\prime}\right)$ ventral, and $\left(\mathbf{C}^{\prime}\right)$ posterior view using non-rigid transformation. (D, E) Direct volume rendered view of the resulting average label images from (D) anterior and (E) posterior, exhibiting deviations primarily in the lobes of the pedunculi of the MBs. Scale bar, $50 \mu \mathrm{m}$

\section{MALE - FEMALE GLOMERULUS COMPARISON}

The glomerular array of ALs of adult female and male T. castaneum consists of about 70 glomeruli (Schachtner et al., 2007). The glomeruli are arranged in two layers around a central coarse neuropil. Anatomical sexual dimorphism in the ALs has been found in several species in which typically males have enlarged glomeruli at the entrance site of the antennal nerve (Schachtner et al., 2005). However, inspection of optical section series did not reveal an obvious morphological difference between A0 female and male ALs.

Searching for glomeruli which we could easily identify from animal to animal, we found an array of eight glomeruli at the lateral dorsal part of the AL, which we could unequivocally detect in $75 \%$ of our preparations. The set of dorso-lateral $(\mathrm{dl})$ glomeruli consists of two larger glomeruli (dl-1, dl-2), three midsized (dl3 , dl-4, dl-7), and three smaller glomeruli (dl-5, dl-6, dl-8) with glomerulus dl-7 always being the most dorsal glomerulus of this set (Figure 5). We reconstructed these eight glomeruli from 10 female and 10 male right ALs with each AL stemming from a different specimen. Like the comparison between the AL volumes and all other reconstructed neuropils, comparison of the glomerular volumes between the two sexes revealed no significant difference in any one of the selected glomeruli (Figure 6).

\section{DISCUSSION}

Tribolium castaneum belongs to the most species-rich and most diverse order in the animal kingdom; Coleoptera comprise about $40 \%$ of all insect species and thus about $30 \%$ of all living animal species (Grimaldi and Engel, 2005; Hunt et al., 2007; Hauser et al., 2008). Worldwide, Tribolium is a major pest for stored grain and grain products and serves as a powerful model for the study of 
Table 1 | Volume measures of neuropil structures in the male and female standard brain of $\boldsymbol{T}$. castaneum. Mean volume (Mean vol.), relative volume (Rel. vol.), standard deviation (SD), relative standard deviation (Rel. SD), standard error (SE), and relative standard error (Rel. SE) of all segmented brain areas in the male $(n=20)$ and female $(n=20)$ standard brain of T. castaneum.

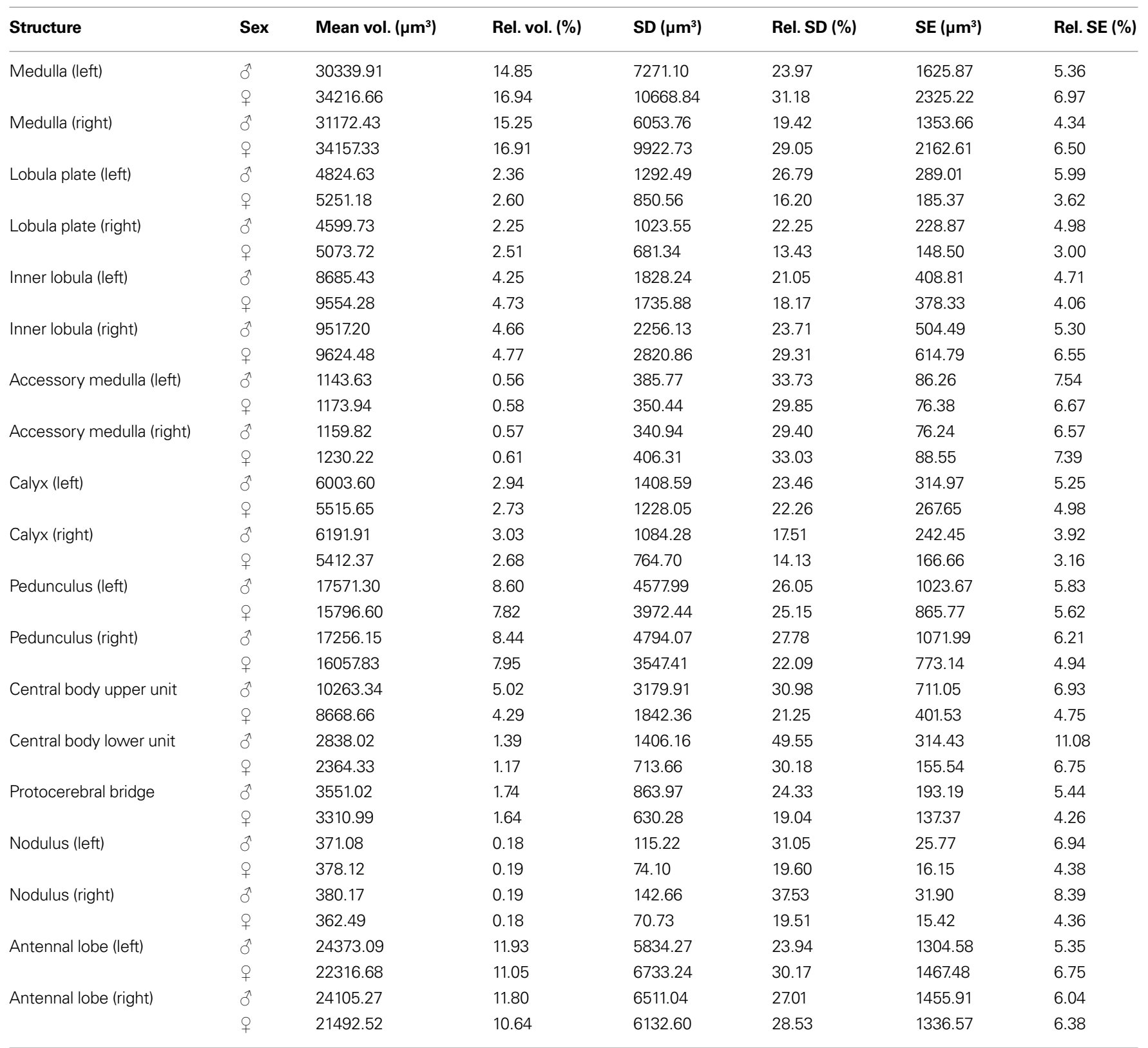

general insect development and evolution. Owing to the feasibility of transgenic approaches, such as powerful reverse genetics based on systemic RNA-interference, directed gene expression, the recently published full genome sequence, easy culturing, a short life cycle, high fecundity and longevity, Tribolium is emerging as a model system at many fronts. With the current study, we provide a reference for future anatomical studies of the brain in connection with genetical manipulation and external parameters as e.g. odor- or social environment and adaptive learning. The average brain atlas comes from freshly eclosed Tribolium of both sexes. Since we are especially interested in the development and plasticity of the olfactory sys- tem, we established an anatomical and volumetric reference of eight selected female and male olfactory glomeruli. Compared to existing insect standard brains, the T. castaneum standard poses - together with the Drosophila standard - the smallest brain.

\section{STANDARD BRAIN GENERATION}

Two methods have been established to obtain a standard insect brain: (1) the VIB protocol, as used for the fruit fly, the desert locust, and the sphinx moth (Rein et al., 2002; Jenett et al., 2006; Kurylas et al., 2008; el Jundi et al., 2009), and (2) the ISA method, as used for the honeybee and also the desert locust (Rohlfing et al., 2004; Brandt 


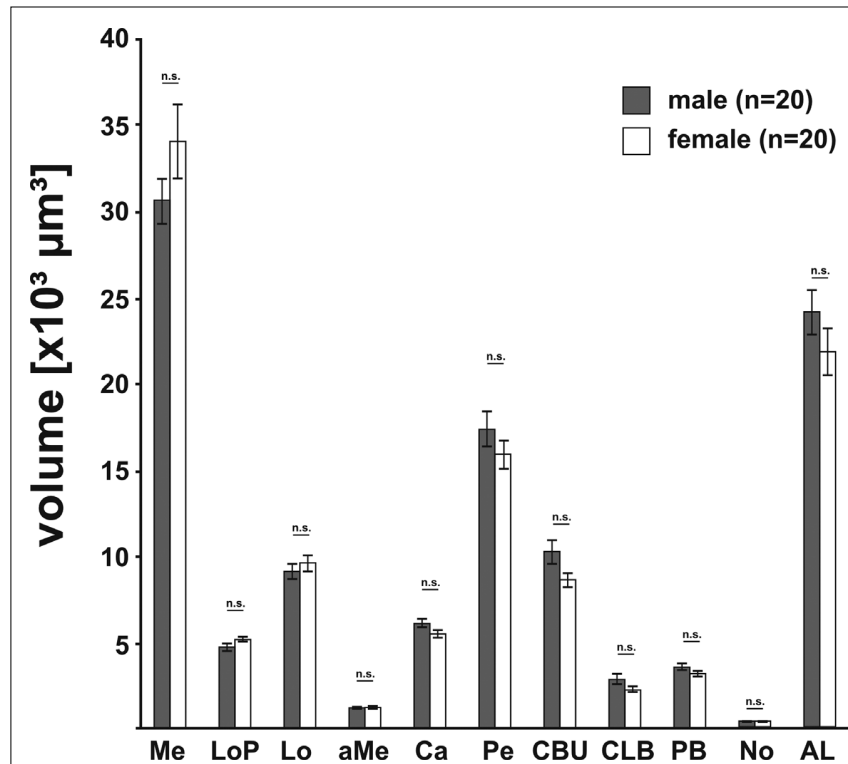

FIGURE 4 | Comparison of neuropil volumes between male (gray) and female (white) brains. The data revealed no significant difference (two-tailed Student's $t$-test) between the volumes of the corresponding neuropils of females and males. Bars, standard error; n.s., not significant.

et al., 2005; Kurylas et al., 2008). The VIB protocol was primarily developed to compare brain areas e.g. between wildtype and genetically manipulated Drosophila, while the ISA method aims to generate a synthetic but realistic standard brain, into which single reconstructed neurons from various individuals could be mapped. The VIB script keeps neuropil volumes rather unchanged, while the ISA method, in contrast, averages anatomical differences on the cost of volume accuracy (Kuß et al., 2007; Kurylas et al., 2008; el Jundi et al., 2009). Both methods require an initial reference or template brain for alignment. While the visualization of the standardized brain areas using the VIB protocol is clearly biased towards this template, the ISA method is thought to be independent of the choice of the template (Guimond et al., 2000; Brandt et al., 2005), with the notable exceptions of orientation and scale. During affine registration in the ISA method, all brains are resized using anisotropic scaling to match the size of the template brain. Thus, the resulting standard volumes of the brain areas generated by the ISA method depend on the choice of the template brain (Rohlfing et al., 2001; el Jundi et al., 2009). Therefore we decided to use the VIB protocol for standardization, since we primarily wanted to compare volumes of neuropils and did not aim for registration of reconstructed neurons (Rø et al., 2007; Kurylas et al., 2008). Given that both methods are established in our lab, a female and a male standard brain calculated by the ISA method could be computed on request.

It has to be noted that our whole mount specimens, like all immunohistochemical preparations, are subjected to considerable tissue shrinking (Bucher et al., 2000; Ott, 2008). Therefore absolute sizes are probably underestimated and make most sense in relative comparisons, i.e. comparisons might only be useful between brains after similar histological treatment. In a previous work, we already showed the usability of $3 \mathrm{D}$ reconstructions to quantify adult plasticity in the male antennal lobe of the sphinx moth (Huetteroth and Schachtner, 2005). Since we carefully checked for animal age, the female and male standard brain will serve as a reference in future quantitative studies using genetical or behavioral approaches.

\section{BRAIN NEUROPIL COMPARISON BETWEEN SEXES}

We found no volumetric differences between females and males in any one of the standardized brain neuropils, including the eight olfactory glomeruli. Anatomical sexual dimorphism in brain structures has been described in a variety of insects primarily with respect to the ALs (for a review see Schachtner et al., 2005). Enlarged glomeruli at the entrance site of the antennal nerve are described for males, as example for cockroaches (Jawlowski, 1948; Neder, 1959; Boeckh et al., 1987), bees (Arnold et al., 1984; Brockmann and Brückner, 2001), ants (Kleineidam et al., 2005; Nishikawa et al., 2008), flies (Kondoh et al., 2003), and moths (reviewed in Anton and Homberg, 1999; Hansson and Anton, 2000). These glomeruli are usually called macroglomeruli or macroglomerular complex (MGC). These glomeruli appear to be involved in pheromone signal processing (reviewed e.g. in Hansson and Christensen, 1999).

Why did we see no sexual dimorphism in the examined brain areas? In principal we expect sexual dimorphism on the level of the brain areas due to sexual specific input (e.g. in the case of the olfactory system a higher number of receptor neurons responsible for the detection of the female pheromone) and/or due to sexual specific behaviors which have to be coordinated from female or male brains in the context of sexual reproduction. The question is whether this dimorphism can be seen on the level of gross brain anatomy like in the case of the sexual specific glomeruli or whether it is due to a few special neurons or and/or different neurochemistry with only little or no effect on gross morphology. As individual variations in neuropil volumes range in the mean at around $20 \%$, we cannot detect anatomical sexual dimorphism smaller than that. Furthermore, we looked at freshly eclosed animals. Thus, the animals are not sexually mature at that time and the brain has just started to get acquainted to the environmental cues including odor information like e.g. pheromones. Currently, we produce a female and male standard brain atlas for 7-day-old animals to examine how brain anatomy is changing in females and males. In M. sexta for example, the sexual dimorphic male glomeruli increase about $40 \%$ in volume during the first 4 days of adulthood (Huetteroth and Schachtner, 2005).

\section{INTERSPECIES BRAIN COMPARISON}

The relative size of a defined brain area is closely related to its apparent importance for the respective animal (e.g. Barton et al., 1995; Gronenberg and Hölldobler, 1999; Schoenemann, 2006). For example in insects larger optic lobes primarily correlate with larger complex eyes containing more photoreceptor cells, while the volume of ALs correlates with the amount of olfactory sensory axons entering this structure. Likewise, the volumes and the organization of higher order integration centers like the mushroom bodies correlate with the complexity of multimodal sensory integration (e.g. Technau, 2007; Molina and O'Donnell, 2008). Additionally, studies in several insect species demonstrated a correlation of volumes of brain areas with age, caste, sex and experience, including primary sensory integration centers like $\mathrm{OL}$ and $\mathrm{AL}$, and higher integration centers like the mushroom bodies (Heisenberg et al., 1995; Barth 

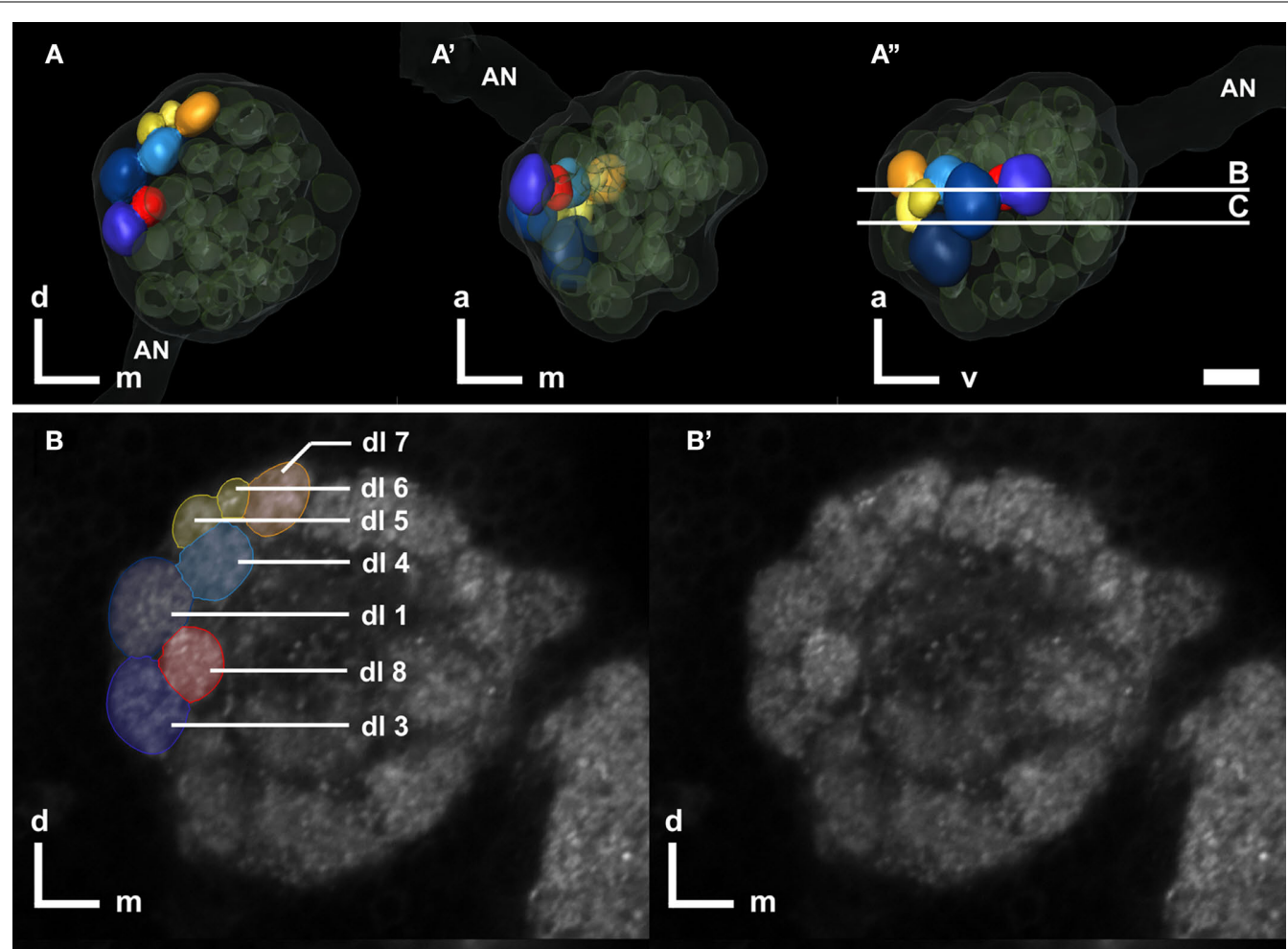

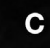

C

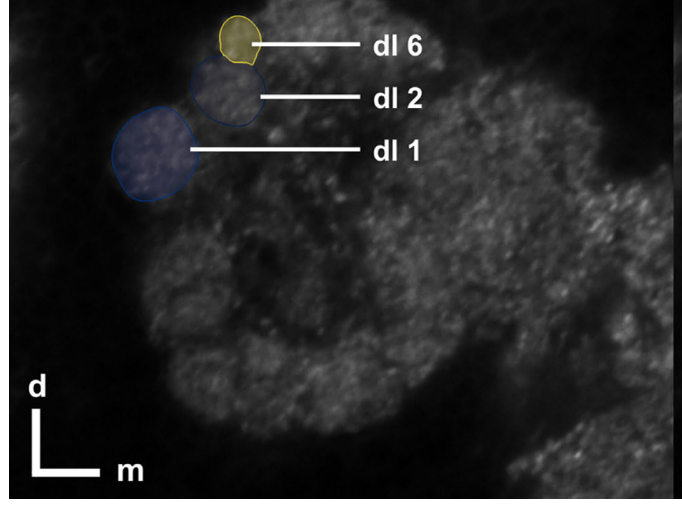

C'

d

FIGURE 5 | Right antennal lobe of a male $T$. castaneum brain. (A-A') Anterior (A), ventral $\left(\mathbf{A}^{\prime}\right)$, and lateral view $\left(\mathbf{A}^{\prime \prime}\right)$ of 3D-reconstructed glomeruli including the antennal nerve (AN, transparent). The eight color coded dorsolateral glomeruli (dl-1 to 8, compare with $\mathbf{B}, \mathbf{C}$ ) can be unequivocally identified in $75 \%$ of all preparations. Other glomeruli are depicted in transparent green; the displayed outline of the AL is shown in transparent gray. The transparent and Heisenberg, 1997; Barth et al., 1997; Sigg et al., 1997; Julian and Gronenberg, 2002; Groh et al., 2006; Technau, 2007; Krofczik et al., 2008; Molina and O’Donnell, 2008; Maleszka et al., 2009; Snell-Rood et al., 2009). So far, the few published insect standard brains give only a limited view on the respective relative volumes of defined brain areas of these species because they provide (1) data for only one sex (with the exception of M. sexta) and (2) one age (D. melanogaster: 5-day-old adult females; Rein et al., 2002; $M$. sexta: freshly eclosed adult females and males; el Jundi et al., 2009), or (3) a mixture of different ages (A. mellifera foragers: Brandt et al., 2005; S. gregaria males: Kurylas et al., 2008). Caste or possible encasement around the $A L$ represents the shape of the whole $A L$. The vertical bars in $\left(\mathbf{A}^{\prime \prime}\right)$ display section levels of $(\mathbf{B}, \mathbf{C})$ and $\left(\mathbf{B}^{\prime}, \mathbf{C}^{\prime}\right)$, respectively. Orientation bars: a, anterior; $d$, dorsal; $m$, medial; v, ventral. (B,C) Frontal confocal sections through the antennal lobe according to $\left(\mathbf{A}^{\prime \prime}\right)$. The eight dorso-lateral glomeruli are manually labeled as reconstructed in AMIRA. (B', $\left.\mathbf{C}^{\prime}\right)$ Confocal sections through the antennal lobe corresponding to (B,C). All scale bars: $10 \mu \mathrm{m}$.

experience dependent differences have also not been taken into account. Thus, a comparison between the relative volumes of the available standardized brain areas has to be judged under these prerequisites (Table 2 ).

In T. castaneum, the optic lobes show the smallest relative volumes, which corresponds to the relative small compound eyes (with 80-83 ommatidia per eye; Friedrich et al., 1996) compared to the other insect species. The ALs in contrast display the largest relative volume, which suggests that Tribolium may primarily rely upon chemical cues, a fact which has been generally proposed for insects inhabiting grain storage areas (Levinson and Levinson, 
1995). Behavioral assays showed that T. castaneum prefers damaged or deteriorated grains to full grains and it responds best to volatiles characteristic of damaged or fungus-infested grain (Trematerra et al., 2000). Tenebrionid beetles, including T. castaneum, produce a rich repertoire of volatiles in a variety of glands. Major volatile secretions, stored in specialized prothoracic and postabdominal glands are the quinones which may act as defensive secretions and antimicrobial substances (Prendeville and Stevens, 2002; Yezerski et al., 2004, 2007). Adult males of T. castaneum possess setiferous glands on the femora of their prothoracic legs (Faustini et al., 1981, 1982), which secrete the highly volatile pheromone, 4,8dimethyldecanal (DMD), which is attractive to females and, to a less extent, to males and was therefore classified as an aggregation pheromone (Suzuki, 1980, 1981). However, the male setiferous glands may not be the major source of DMD (Bloch Qazi et al., 1998; Arnaud et al., 2002). Moreover, a recent electrophysiological investigation on Tribolium volatile compounds led to the conclusion that several beetle produced compounds, in addition to DMD, may be part of a complex aggregation pheromone system (Verheggen et al., 2007).

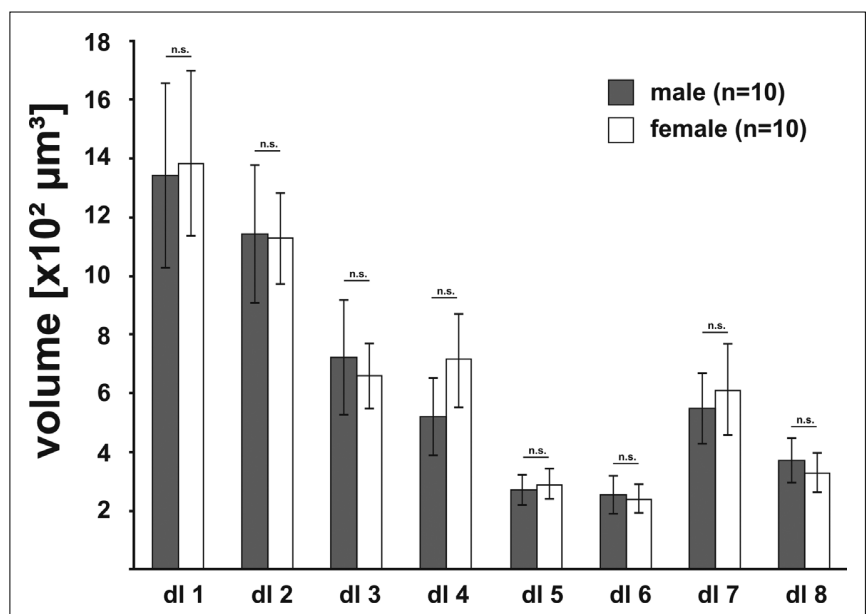

FIGURE 6 | Comparison of the volumes of the eight identified glomeruli between right male (gray; $n=10$ ) and right female (white; $n=10$ ) ALs, revealed no significant difference between the sexes (two-tailed student t-test). Bars, standard error; n.s., not significant.
Mushroom bodies (MBs) are generally associated with higher integration processes and learning (e.g. Menzel, 2001; Heisenberg, 2003), but might also serve a general function in the control of behavior (e.g. Huber, 1955a, b; Erber et al., 1987; Zars, 2000; Strausfeld et al., 2009). While the social honeybee by far exhibits the largest relative MB volumes, interestingly, Tribolium is second before Drosophila (Table 2). A recent study found similar development of MBs in Tribolium and Drosophila, with the remarkable difference, that adult neurogenesis occurs in Tribolium (Zhao et al., 2008). MBs vary in relative size in different nymphalid butterflies, without a correlation with optic or antennal lobe size. Heliconius charitonius for example has almost four times bigger mushroom bodies than other butterflies of that family (Sivinsky, 1989). This is attributed to its relative long life combined with its occurrence in forest habitats with only scattered food resources, and a shared resting place with conspecifics. As discussed by the author, remembering a common resting place and good food sites might be a higher evolutionary constraint for learning ability than finding proper egg-laying sites, which does not necessarily involve memory tasks (Sivinsky, 1989). For the ant Cataglyphis, Wehner et al. (2007) discussed social interaction rather than food gathering for being responsible of bigger mushroom bodies compared to other ant species, an idea originally brought up by von Alten (1910). The relative large size of the MBs in Tribolium suggests a high integrative capacity which may include olfactory components (see above). Additionally, a life expectation of months to years and a long reproductive period (Dawson, 1977) might also justify an investment into a brain structure dedicated to higher integration, memory, and behavioral control.

The function of the central complex still remains elusive, but is probably best described as a central coordinating function in sensory and motor integration (for reviews see Strauss, 2002; Wessnitzer and Webb, 2006; Homberg, 2008). Regarding the relative volume of the central complex, the sum of relative ellipsoid body volume and fan-shaped body volume in the fly and the relative volume of upper and lower units in locust, honeybee, moth, and beetle, Tribolium exceeds even that of the fly. This suggests a more complex function than in all other examined insects. In this context, it would be interesting to have comparable standardized central complex volumes of other coleopterans with different lifestyles e.g. water beetles or non-flying beetles.

Table 2 | Comparison of relative neuropilar volumes between different insect species obtained from five different insect orders, namely Diptera (Drosophila melanogaster. Rein et al., 2002), Hymenoptera (Apis mellifera: Brandt et al., 2005), Orthoptera (Schistocerca gregaria: Kurylas et al., 2008), Lepidoptera (M. sexta, el Jundi et al., 2009), and Coleoptera (T. castaneum, this work). We included the sex and the number of individuals which were used for respective standardization. Only neuropils which have complements in all examined animals were compared (optic lobes: medulla, lobula complex, and lobula plate; antennal lobes, mushroom bodies including calyces and pedunculi, upper and lower unit of the central body).

\begin{tabular}{|c|c|c|c|c|c|c|c|}
\hline \multirow{2}{*}{$\begin{array}{l}\begin{array}{l}\text { Order } \\
\text { Species }\end{array} \\
\text { Sex }\end{array}$} & \multirow{2}{*}{$\begin{array}{l}\text { Diptera } \\
\text { D. melanogaster } \\
\text { ㅇ }\end{array}$} & \multirow{2}{*}{$\begin{array}{l}\text { Hymenoptera } \\
\text { A. mellifera } \\
\Varangle\end{array}$} & \multirow{2}{*}{$\begin{array}{l}\text { Orthoptera } \\
\text { S. gregaria } \\
\qquad \lesssim\end{array}$} & \multicolumn{2}{|c|}{$\begin{array}{l}\text { Lepidoptera } \\
\text { M. sexta }\end{array}$} & \multicolumn{2}{|c|}{$\begin{array}{l}\text { Coleoptera } \\
\text { T. castaneum }\end{array}$} \\
\hline & & & & 우 & 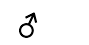 & 우 & 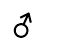 \\
\hline Number of individuals & 28 & 20 & 10 & 12 & 12 & 20 & 20 \\
\hline Optic lobes (\%) & 79.65 & 57.91 & 72.67 & 79.36 & 77.35 & 50,06 & 45,05 \\
\hline Antennal lobes (\%) & 9.36 & 8.53 & 9.68 & 12.86 & 15.09 & 22,41 & 24,50 \\
\hline Mushroom bodies (\%) & 7.56 & 32.65 & 15.98 & 6.87 & 6.76 & 21,88 & 23,83 \\
\hline
\end{tabular}


With the current study we provide a standard female and male brain of freshly eclosed T. castaneum. These standard brains will serve as a useful tool to study brain development and brain plasticity.

\section{ACKNOWLEDGMENTS}

The authors thank Dr. Erich Buchner (University of Würzburg, Germany) for kindly providing the anti-Synapsin antibody and Drs. Jochen Trauner and Gregor Bucher for supplying us with starter colonies of Tribolium. The authors are also grateful to Drs.

\section{REFERENCES}

Anton, S., and Homberg, U. (1999). Antennal lobe structure. In Insect Olfaction, B. S. Hansson, ed. (Berlin, Springer), pp. 97-124.

Arnaud, L., Lognay, G., Verscheure, M., Leenaers, L., Gaspar, C., and Haubruge, E. (2002). Is dimethyldecanal a common aggregation pheromone of Tribolium flour beetles? J. Chem. Ecol. 28, 523-532.

Arnold, G., Masson, C., and Budharugsa, S. (1984). Demonstration of a sexual dimorphism in the olfactory pathways of the drones of Apis mellifica $L$. (Hymenoptera, Apidae). Experientia $40,723-725$.

Barth, M., and Heisenberg, M. (1997). Vision affects mushroom bodies and central complex in Drosophila melanogaster. Learn. Mem. 4, 219-229.

Barth, M., Hirsch, H. V., Meinertzhagen, I. A., and Heisenberg, M. (1997). Experience-dependent developmental plasticity in the optic lobe of Drosophila melanogaster. J. Neurosci. 17, 1493-1504.

Barton, R. A., Purvis, A., and Harvey, P. H. (1995). Evolutionary radiation of visual and olfactory brain systems in primates, bats and insectivores. Philos. Trans. $R$. Soc. Lond., B, Biol. Sci. 348, 381-392.

Berghammer, A., Bucher, G., Maderspacher, F., and Klingler, $M$. (1999). A system to efficiently maintain embryonic lethal mutations in the flour beetle Tribolium castaneum. Dev. Genes Evol. 209, 382-389.

Bloch Qazi, M. C., Boake, C. R. B., and Lewis, S. M. (1998). The femoral setiferous glands of Tribolium castaneum males and production of the pheromone 4,8-dimethyldecanal. Entomol. Exp. Appl. 89, 313-317.

Boeckh, J., Ernst, K. D., and Selsam, P. (1987). Neurophysiology and neuroanatomy of the olfactory pathway in the cockroach. Ann. N. Y. Acad. Sci. 510, 39-43.

Bonneton, F. (2008). The beetle by the name of Tribolium: typology and etymology of Tribolium castaneum Herbst, 1797. Insect Biochem. Mol. Biol. 38, 377-379.

Brandt, R., Rohlfing, T., Rybak, J., Krofczik, S., Maye, A., Westerhoff, M., Hege, H.
C., and Menzel, R. (2005). Threedimensional average-shape atlas of the honeybee brain and its applications. $J$. Comp. Neurol. 492, 1-19.

Brockmann, A., and Brückner, D. (2001) Structural differences in the drone olfactory system of two phylogenetically distant Apis species, A. florea and A. mellifera. Naturwissenschaften 88, 78-81.

Bucher, D., Scholz, M., Stetter, M., Obermayer, K., and Pflüger, H. J. (2000). Correction methods for threedimensional reconstructions from confocal images: I. Tissue shrinking and axial scaling. J. Neurosci. Methods 100, 135-143.

Bucher, G., Scholten, J., and Klingler, M. (2002). Parental RNAi in Tribolium (Coleoptera). Curr. Biol. 12, R85-R86.

Chapman, R. N. (1926). Inhibiting the process of metamorphosis in the confused flour beetle (Tribolium confusum Duval). J. Exp. Zool. 45, 293-299.

Dawson, P. S. (1977). Life history strategy and evolutionary history of Tribolium flour beetles. Evolution 31, 226-229.

el Jundi, B., Huetteroth, W., Kurylas, A.E., and Schachtner, J. (2009). Anisometric brain dimorphism revisited: implementation of a volumetric 3D standard brain in Manduca sexta. J. Comp. Neurol. 517, 210-225.

Erber,J., Homberg, U. and Gronenberg, W. (1987). Functional roles of the mushroom bodies in insects. In Arthropod brain: Its evolution, Development, Structure, and Functions, A.P.Gupta, ed. (New York, NY, Wiley), pp. 485-511.

Faustini, D. L., Burkholder, W. E., and Laub, R. J. (1981). Sexually dimorphic setiferous sex patch in the male red flour beetles Tribolium castaneum (Herbst) (Coleoptera: Tenebrionidae): site of aggregation pheromone production. J. Chem. Ecol. 7, 465-480.

Faustini, D. L., Post, D. C., and Burkholder, W. E. (1982). Histology of aggregation pheromone gland in the red flour beetle. Ann. Entomol. Soc. Am. 75, 187-190.

Friedrich, M., Rambold, I., and Melzer, R. R. (1996). The early stages of ommaTribolium castaneum (Coleoptera; Tenebrionidae). Dev. Genes Evol. 206, 136-146. tidial development in the flour beetle

Uwe Homberg, Ernst Wimmer and Stefan Schütz for many fruitful discussions and Martina Kern and Silke Redelfs for expert technical assistance. This work was supported by a DFG grant (SCHA 678/13-1) to Joachim Schachtner.

\section{SUPPLEMENTARY MATERIAL}

The Supplementary Material for this article can be found online at http://www.frontiersin.org/systemsneuroscience/paper/10.3389/ neuro.06/003.2010/

Fukushima, R., and Kanzaki, R. (2009). Modular subdivision of mushroom bodies by kenyon cells in the silkmoth J. Comp. Neurol. 513, 315-330.

Grimaldi, D., and Engel, M. S. (2005) Evolution of the Insects. Cambridge, Cambridge University Press.

Groh,C.,Ahrens, D., and Rössler,W.(2006) Environment- and age-dependent plasticity of synaptic complexes in the mushroom bodies of honeybee queens. Brain Behav. Evol. 68, 1-14.

Groh, C., Tautz, J., and Rössler, W. (2004). Synaptic organization in the adult honey bee brain is influenced by brood-temperature control during pupal development. Proc. Natl. Acad. Sci. U.S.A. 101, 4268-4273.

Gronenberg, W., and Hölldobler, B. (1999). Morphologic representation of visual and antennal information in the ant brain. J. Comp. Neurol. 412, 229-240.

Guimond, A., Meunier, J., and Thirion, J. P. (2000). Average brain models: convergence study. Comput. Vis. Image Underst. 77, 192-210.

Hansson, B. S., and Anton, S. (2000) Function and Morphology of the Antennal Lobe: New Developments. Annu. Rev. Entomol. 45, 203-231.

Hansson, B. S. and Christensen, T. A. (1999). Functional characteristics of the antennal lobe. In Insect Olfaction. B. S. Hansson, ed. (Berlin, Springer). pp. 126-162.

Happ, G. M. (1968). Quinone and hydrocarbon production in the defensive glands of Eleodeslongicollis and Tribolium castaneum (Coleoptera, Tenebrionidae). J. Insect Physiol. 14, 1821-1837.

Hauser, F., Cazzamali, G., Williamson, M., Park, Y., Li, B., Tanaka, Y., Predel, R., Neupert, S., Schachtner, J. Verleyen, P., and Grimmelikhuijzen, C. (2008). A genome-wide inventory of neurohormone GPCRs in the red flour beetle Tribolium castaneum. Front. Neuroendocrinol. 29, 142-165. doi:10.1016/j.yfrne.2007.10.003.

Heisenberg, M. (2003). Mushroom body memoir: from maps to models. Nat. Rev. Neurosci. 4, 266-275.

Heisenberg, M., Heusipp, M., and Wanke, C. (1995). Structural plasticity in the
Drosophila brain. J. Neurosci. 15, 1951-1960.

Hildebrand, J. G., and Shepherd, G. M. (1997). Mechanisms of olfactory discrimination: convergent evidence for common principles across phyla. Annu. Rev. Neurosci. 20, 595-611.

Homberg, U. (2008). Evolution of the central complex in the arthropod brain with respect to the visual system. Arthropod Struct. Dev. 37, 347-362.

Huber, F. (1955a). Über die Funktion der Pilzkörper (Corpora pedunculata) beim Gesang der Keulenheuschrecke Gomphocerus rufus L. (Acridiidae) Naturwissenschaften 20, 566-567.

Huber, F. (1955b). Sitz und Bedeutung nervöser Zentren für Instinkthandlungen beim Männchen von Gryllus campestris L. $Z$ Tierpsychol. 12, 12-48.

Huetteroth, W., and Schachtner, J. (2005). Standard three-dimensional glomeruli of the Manduca sexta antennal lobe: a tool to study both developmental and adult neuronal plasticity. Cell Tissue Res. 319, 513-524.

Hunt, T., Bergsten, J., Levkanicova, Z., Papadopoulou, A., St. John, O., Wild R.,Hammond, P.M., Ahrens, D., Balke, M., Caterino, M. S., Gómez-Zurita, J., Ribera, I., G. Barraclough, T. G., Bocakova, M., Bocak, L., and Vogler, A. P. (2007). A Comprehensive phylogeny of beetles reveals the evolutionary origins of a superradiation. Science 318, 1913-1916.

Jawlowski, H. (1948). Studies on the insect brain. Ann. Univ. Mariae Curie Sklodowska C 3, 1-30.

Jenett, A., Schindelin, J. E., and Heisenberg, M. (2006). The virtual insect brain protocol: creating and comparing standardized neuroanatomy. $B M C$ Bioinformatics 7, 544.

Julian, G. E., and Gronenberg, W. (2002). Reduction of brain volume correlates with behavioral changes in queen ants. Brain Behav. Evol. 60, 152-164.

Klagges, B. R., Heimbeck, G., Godenschwege, T. A., Hofbauer, A., Pflugfelder, G. O., Reifegerste, R., Reisch, D., Schaupp, M., Buchner, S., and Buchner, E. (1996). Invertebrate synapsins: a single gene codes for 
several isoforms in Drosophila. J. Neurosci. 16, 3154-3165.

Kleineidam, C. J., Obermayer, M., Halbich, W., and Rössler, W. (2005). A macroglomerulus in the antennal lobe of leaf-cutting ant workers and its possible functional significance. Chem. Senses 30, 383-392.

Klingler, M. (2004). Tribolium. Curr. Biol. 24, R639-R640.

Kondoh, Y., Kaneshiro, K. Y., Kimura, K., and Yamamoto, D. (2003). Evolution of sexual dimorphism in the olfactory brain of Hawaiian Drosophila. Proc. Biol. Sci. 270, 1005-1013.

Krofczik, S., Khojasteh, U., de Ibarra, N. H., and Menzel, R. (2008). Adaptation of microglomerular complexes in the honeybee mushroom body lip to manipulations of behavioral maturation and sensory experience. Dev. Neurobiol. 68, 1007-1017.

Kuß, A., Hege, H. C., Krofczik, S., and Borner, J. (2007). Pipeline for the creation of surface-based averaged brain atlases. In Proceedings of Winter School of Computer Graphics Vol. 1 pp. 17-24.

Kurylas, A. E., Rohlfing, T., Krofczik, S., Jenett, A., and Homberg, U. (2008). Standardized atlas of the brain of the desert locust, Schistocerca gregaria. Cell Tissue Res. 333, 125-145.

Levinson, A., and Levinson, H. (1995). Reflections on structure and function of pheromone glands in storage insect species. Anz. Schädlingskd. Pfl. Umwelt. 67, 99-118.

Maleszka, J., Barron, A. B., Helliwell, P. G., and Maleszka, R. (2009). Effect of age, behaviour and social environment on honey bee brain plasticity. J. Comp. Physiol. A 195, 733-740.

Menzel, R. (2001). Searching for the memory trace in a mini-brain, the honeybee. Learn. Mem. 8, 53-62.

Molina, Y., and O'Donnell, S. (2008). Age, sex, and dominance-related mushroom body plasticity in the paperwasp Mischocyttarus mastigophorus. Dev. Neurobiol. 68, 950-959.

Neder,R. (1959).Allometrisches Wachstum von Hirnteilen bei drei verschieden großen Schabenarten. Zool. Jahrb. Abt. Allg. Zool. Physiol. 77, 411-467.

Nishikawa, M., Nishino, H., Misaka, Y., Kubota, M., Tsuji, E., Satoji, Y., Ozaki, M., and Yokohari, F. (2008). Sexual dimorphism in the antennal lobe of the ant Camponotus japonicus. Zool. Sci. 25, 195-204.

Ott, S. R. (2008). Confocal microscopy in large insect brains: zinc-formaldehyde fixation improves synapsin immunostaining and preservation of morphology in whole-mounts. $J$. Neurosci. Methods 172, 220-230.

Prendeville, H. R., and Stevens, L. (2002). Microbe inhibition by Tribolium flour beetles varies with beetle species, strain, sex, and microbe group. J. Chem. Ecol. 28, 1183-1190.

Rein, K., Zöckler, M., Mader, M. T., Grübel.C., and Heisenberg, M. (2002). The Drosophila standard brain. Curr. Biol. 12, 227-231.

Richards, S. Gibbs, R. A., Weinstock, G. M., Brown, S. J., Denell, R., Beeman, R. W., Gibbs, R., Beeman, R. W., Brown, S. J., Bucher, G., Friedrich, M., Grimmelikhuijzen, C. J., Klingler, M., Lorenzen, M., Richards, S., Roth, S., Schröder, R., Tautz, D., Zdobnov, E. M, Muzny, D., Gibbs, R. A., Weinstock, G. M., Attaway, T., Bell, S., Buhay, C. J., Chandrabose, M. N., Chavez, D., Clerk-Blankenburg, K. P., Cree, A., Dao, M., Davis, C., Chacko, J., Dinh, H., Dugan-Rocha, S., Fowler, G., Garner, T. T., Garnes, J., Gnirke, A., Hawes, A., Hernandez, J., Hines, S., Holder, M., Hume, J., Jhangiani, S. N., Joshi, V., Khan, Z. M., Jackson, L., Kovar, C., Kowis, A., Lee, S., Lewis, L. R., Margolis, J., Morgan, M., Nazareth, L. V., Nguyen, N., Okwuonu, G., Parker, D., Richards, S., Ruiz, S. J., Santibanez, J., Savard, J., Scherer, S. E., Schneider, B., Sodergren, E., Tautz, D., Vattahil, S., Villasana, D., White, C. S., Wright, R., Park, Y., Beeman, R. W., Lord, J., Oppert, B., Lorenzen, M., Brown, S., Wang, L., Savard, J., Tautz, D., Richards, S., Weinstock, G., Gibbs, R. A., Liu, Y., Worley, K., Weinstock, G., Elsik, C. G., Reese, J. T., Elhaik, E., Landan, G., Graur, D., Arensburger, P., Atkinson, P., Beeman, R. W., Beidler, J., Brown, S. J., Demuth, J. P., Drury, D. W., Du, Y. Z., Fujiwara, H., Lorenzen, M., Maselli, V., Osanai, M., Park, Y., Robertson, H. M., Tu, Z., Wang, J. J., Wang, S., Richards, S., Song, H., Zhang, L., Sodergren, E., Werner, D., Stanke, M., Morgenstern, B., Solovyev, V., Kosarev, P., Brown, G., Chen, H. C., Ermolaeva, O., Hlavina, W., Kapustin, Y., Kiryutin, B., Kitts, P., Maglott, D., Pruitt, K., Sapojnikov, V., Souvorov, A., Mackey, A. J., Waterhouse, R. M., Wyder, S., Zdobnov, E. M., Zdobnov, E. M., Wyder, S., Kriventseva, E. V., Kadowaki, T., Bork, P., Aranda, M., Bao, R., Beermann, A., Berns, N., Bolognesi, R., Bonneton, F., Bopp, D., Brown, S. J., Bucher, G., Butts, T., Chaumot, A., Denell, R. E., Ferrier, D. E.,Friedrich, M., Gordon, C. M.,Jindra, M., Klingler, M., Lan, Q., Lattorff, H. M., Laudet, V., von Levetsow, C., Liu, Z., Lutz, R., Lynch, J. A., da Fonseca, R.N., Posnien, N., Reuter, R., Roth, S., Savard, J., Schinko, J. B., Schmitt, C., Schoppmeier, M., Schröder, R., Shippy, T. D., Simonnet, F., MarquesSouza, H., Tautz, D., Tomoyasu, Y., Trauner, J., Van der Zee, M., Vervoort, M., Wittkopp, N., Wimmer, E.A.,
Yang, X., Jones, A. K., Sattelle, D. B., Ebert, P. R., Nelson, D., Scott, J. G., Beeman, R. W., Muthukrishnan, S., Kramer, K. J., Arakane, Y., Beeman, R. W., Zhu, Q., Hogenkamp, D., Dixit, R., Oppert, B., Jiang, H., Zou, Z. Marshall, J., Elpidina, E., Vinokurov, K., Oppert, C.,Zou,Z., Evans, J., Lu,Z., Zhao, P., Sumathipala, N., Altincicek, B., Vilcinskas, A., Williams, M., Hultmark, D., Hetru, C., Jiang, H., Grimmelikhuijzen, C. J., Hauser, F., Cazzamali, G., Williamson, M., Park, Y., Li, B., Tanaka, Y., Predel, R., Neupert, S., Schachtner, J., Verleyen, P., Raible, F. Bork, P., Friedrich, M., Walden, K.K., Robertson, H. M., Angeli, S., Forêt, S., Bucher, G., Schuetz, S., Maleszka, R., Wimmer, E. A., Beeman, R. W. Lorenzen, M., Tomoyasu, Y., Miller, S. C., Grossmann, D., and Bucher, G. (The Tribolium Genome Sequencing Consortium) (2008). The genome of the model beetle and pest Tribolium castaneum. Nature 452, 949-955.

Rohlfing, T., Brandt, R., Maurer, C. R. Jr., and Menzel, R. (2001). Bee brains, $\mathrm{B}$-splines and computational democracy: generating an average shape atlas. In IEEE Workshop on Mathematical Methods in Biomedical Image Analysis, Kauai, HI 2001, L. Staib, ed. (Los Alamitos, CA, IEEE Computer Society), pp. 187-194.

Rø, H., Müller, D., and Mustaparta, H. (2007). Anatomical organization of antennal lobe projection neurons in the moth Heliothis virescens. J. Comp. Neurol. 500, 658-675.

Rohlfing, T., Brandt, R., Menzel, R., and Maurer. C. R. Jr. (2004). Evaluation of atlas selection strategies for atlas-based image segmentation with application to confocal microscopy images of bee brains. Neuroimage 21, 1428-1442.

Schachtner, J., Goetz, B., Dippel, S., Dreyer, D. and Huetteroth, W. (2007). Metamorphic development of the antennal lobes of the red flour beetle Tribolium castaneum:3D-reconstruction and neurochemistry. Program No. 135.2/F14. 2007 Neuroscience Meeting Planner. San Diego, CA: Society for Neuroscience (online).

Schachtner, J., Schmidt, M., and Homberg, U. (2005). Organization and evolutionary trends of primary olfactory brain centers in Tetraconata (Crustacea+Hexapoda). Arthropod Struct. Dev. 34, 257-299.

Schoenemann, P. T. (2006). Evolution of the size and functional areas of the human brain. Annu. Rev. Anthropol. 35, 379-406.

Settembrini, B. P, and Villar, M. J. (2005) FMRFamide-like immunocyrochemistry in the brain and subesophageal ganglion of Triatoma infestans (Insecta: Heteroptera). Coexpression with $\mathrm{B}$-pigment-dispersing hormone and small cardioactive peptide. Cell Tissue Res. 321, 299-310.

Sigg, D., Thompson, C.M., and Mercer,A. R. (1997). Activity-dependent changes to the brain and behavior of the honey bee, Apis mellifera (L.). J. Neurosci. 17, 7148-7156.

Sivinsky, J. (1989). Mushroom body development in nymphalid butterflies: a correlate of learning? J. Insect Behav. 2, 277-283.

Sjöholm, M., Sinakevitch, I., Ignell, R., Strausfeld, N. J., and Hansson, B. S. (2005). Organization of kenyon cells in subdivisions of the mushroom bodies of a lepidopteran insect. J. Comp. Neurol. 491, 290-304.

Snell-Rood, E. C., Papaj, D. R., and Gronenberg, W. (2009). Brain size: a global or induced cost of learning? Brain Behav. Evol. 73, 111-128.

Sokoloff, A. (1966). The Genetics of Tribolium and Related Species. Advances in Genetics, Suppl. 1. New York, Academic Press.

Sokoloff, A. (1974, 1977). The Biology of Tribolium with Special Emphasis on Genetic Aspects, Vol. II and III. Oxford, Clarendon Press/Oxford University Press.

Strausfeld, N. J. (2005). The evolution of crustacean and insect optic lobes and the origins of chiasmata. Arthropod Struct. Dev. 34, 235-256.

Strausfeld, N.J., Hansen, L., Li, Y., Gomez, R. S., and Ito, K. (1998). Evolution, discovery, and interpretations of arthropod mushroom bodies. Learn. Mem. 5, 11-37.

Strausfeld, N. J., Sinakevitch, I., Brown, S. M., and Farris, S. M. (2009). Ground plan of the insect mushroom body: functional and evolutionary implications. J. Comp. Neurol. 513, 265-291.

Strauss, R. (2002). The central complex and the genetic dissection of locomotor behaviour. Curr. Opin. Neurobiol. $12,633-638$.

Suzuki, T. (1980). 4,8-Dimethyldecanal: the aggregation pheromone of the flour beetles Tribolium castaneum and T. confusum (Coleoptera: Tenebrionidae). Agric. Biol. Chem. 44, 2519-2520.

Suzuki, T. (1981). A facile synthesis of 4,8-dimethyldecanal, aggregation pheromone of flour beetles, and its analogs. Agric. Biol. Chem. 45, 2641-2643.

Technau, G. M. (2007). Fiber number in the mushroom bodies of adult Drosophila melanogaster depends on age, sex and experience. J. Neurogenet. 21, 183-196.

Tomoyasu, Y., and Denell, R. E. (2004). Larval RNAi in Tribolium (Coleoptera) for analyzing adult development. Dev. Genes. Evol. 214, 575-578. 
Tomoyasu, Y., Miller, S. C., Tomita, S., Schoppmeier, M., Grossmann, D., and Bucher, G. (2008). Exploring systemic RNA interference in insects: a genome-wide survey for RNAi genes in Tribolium. Genome Biol. 9, R10.

Trematerra, P., Sciarreta, A., and Tamasi, E. (2000). Behavioural responses of Oryzaephilus surinamensis, Tribolium castaneum and Tribolium confusum to naturally and artificially damaged durum wheat kernels. Entomol. Exp. Appl. 94, 195-200.

Utz, S., Huetteroth, W., Vömel, M., and Schachtner,J. (2008). Mas-allatotropin in the developing antennal lobe of the sphinx moth Manduca sexta: distribution, time course, developmental regulation, and colocalization with other neuropeptides. Dev. Neurobiol. $68,123-142$.
Verheggen, F., Ryne, C., Olsson, P. O., Arnaud, L., Lognay, G., Högberg, H.E., Persson, D., Haubruge, E., and Löfstedt, C. (2007). Electrophysiological and behavioral activity of secondary metabolites in the confused flour beetle, Tribolium confusum. J. Chem. Ecol. 33, 525-539.

von Alten, H. (1910). Zur Phylogenie des Hymenopterengehirns. Jena. $Z$. Naturwiss. 46, 511-590.

Wehner, R., Fukushi, T., and Isler, K. (2007). On being small: brain allometry in ants. Brain Behav. Evol. 69, 220-228.

Wessnitzer, J., and Webb, B. (2006). Multimodal sensory integration in insects - towards insect brain control architectures. Bioinspir. Biomim. 1, 63-75.

Yezerski, A., Ciccone, C., Rozitski, J., and Volingavage, B. (2007). The effects of a naturally produced benzoquinone on microbes common to flour. J. Chem. Ecol. 33, 1217-1225.

Yezerski, A., Gilmor, T. P., and Stevens, L. (2004). Genetic analysis of benzoquinone production in Tribolium confusum. J. Chem. Ecol. 30, 1034-1044.

Zars, T. (2000). Behavioral functions of the insect mushroom bodies. Curr. Opin. Neurobiol. 10, 790-795.

Zhao, X., Coptis, V., and Farris, S. M. (2008). Metamorphosis and adult development of the mushroom bodies of the red flour beetle, Tribolium castaneum. Dev. Neurobiol. 68, 1487-1502.

Conflict of Interest Statement: The authors declare that the research was conducted in the absence of any commercial or financial relationship that could be construed as a potential conflict of interest.
Received: 05 September 2009; paper pending published: 28 November 2009; accepted: 18 January 2010; published online: 03 March 2010.

Citation: Dreyer D, Vitt H, Dippel $S$, Goetz B, el Jundi B, Kollmann M, Huetteroth $W$ and Schachtner J (2010) $3 D$ standard brain of the red flour beetle Tribolium castaneum: a tool to study metamorphic development and adult plasticity. Front. Syst. Neurosci. 4:3. doi: 10.3389/neuro.06.003.2010

Copyright (๑ 2010 Dreyer, Vitt, Dippel, Goetz, el Jundi, Kollmann, Huetteroth and Schachtner. This is an open-access article subject to an exclusive license agreement between the authors and the Frontiers Research Foundation, which permits unrestricted use, distribution, and reproduction in any medium, provided the original authors and source are credited. 